\title{
A CLOSER LOOK AT FOOTERS IN WEBSITE DESIGN
}

\author{
James J. Cappel, Central Michigan University,james.cappel@cmich.edu \\ Zhenyu Huang, Central Michigan University, zhenyu.huang@cmich.edu
}

\begin{abstract}
While the importance of website usability is rather well established in the literature, until recently few website designers have looked to the footer as a way to promote usability. That notion appears to be changing as more websites seem to be moving from a traditional (perfunctory) footer to one that is designed to deliver real value to the user experience. To date there has been little research to examine company website design practices with respect to the footer. This exploratory study addresses this issue through a content analysis of INC. 500 company websites. It provides insight into company website practices so organizations can take a "fresh look" at the footer as a potential way for improving the usability of their website design.
\end{abstract}

Keywords: Website design/usability; Internet/Intranet/Extranet; Systems analysis and design

\section{INTRODUCTION}

According to ISO standard 9241-11, "Usability refers to the extent to which a product can be used by specified users to achieve specified goals with effectiveness, efficiency, and satisfaction in a specified context of use" [15]. The importance of usability for website design has been stressed by a number of writers [e.g., 4, 6, 7, 8]. They point out that if website usability is not achieved, an organization runs the risks of users becoming confused or frustrated, leaving the site, having a negative image of the organization, and losing their business to competitor's sites. Prior research studies $[1,5]$ have also been conducted to examine the extent to which website design practices conform to the guidelines put forth by prominent usability writers.

In truth, there are a myriad number of ways an organization can employ to achieve usability in their website design. These encompass having an intuitive organization scheme to the site, including a breadcrumb trail, search box, or other navigation options, following standard web conventions, and providing the functionality that users want and expect from the site.

Traditionally, the footer has rarely been considered as a design element to promote website usability. Footers at company websites have usually been presented as a single line in fine print at the bottom of a Web page. They have commonly included a copyright statement and links such as: "about us," "contact," "help", "privacy policy," or "terms and conditions" $[2,8]$. Thus, the traditional focus of the footer has been to provide administrative functions and legal disclaimers. The implicit assumption is that since few users are likely to care about or use these options, it is adequate to bury them at the bottom of the page. Since this practice has the effect of minimizing the amount of vertical space required for the footer, it is also consistent with the view of some designers to keep Web pages shorter to minimize the amount of scrolling required of users.

In more recent years, more organizations seem to have expanded the form and function of their website footer. Under this approach, footers are considerably larger in appearance, leading to some authorities referring to them as "fat footers." These expanded footers commonly make available organized columns of the most important or most frequently visited links so users can access them conveniently from any location at a site. These footers may also include short signup or contact forms, RSS feed links or social media links or icons [13]. Since these footers are designed to add value to the user experience, they have also been called "functional footers." For purposes of this paper, the terms "functional footer," "fat footer," or "expanded footer" are used interchangeably. While using larger footers leads to a vertically longer Web page that may result in requiring users to scroll to view content, some designers contend this tradeoff is worthwhile in leading to promoting usability and an overall better Web page design. 


\section{Issues in Information Systems \\ Volume 14, Issue 2, pp.182-185, 2013}

Anecdotal evidence suggests some website designers may confuse the functional footer with a site map. In an electronic discussion board, a Web designer commented, "I have been calling these 'sitemap footers' because they often replace the function of the old 'sitemap' link" [13]. However, a second participant in the same discussion thread commented, "I prefer not to call them a 'sitemap footer' as they are a departure from the hierarchical structure of the main navigation and often a subset of what I would normally show in a sitemap" [13]. The latter comment appears to be more accurate as a functional footer is usually not as comprehensive in detailing the contents of a website as a site map.

Yet based on a literature review by the authors of the works of prominent usability experts $[4,6,7,9,14]$, no formal definition of a "functional footer" has been offered by an authoritative source. A leading Web usability organization, the Nielsen Norman Group (NNG), has recognized the presence of fat footers at company websites and has suggested these footers can be a positive design practice; but NNG has not presented a definition of a "functional footer" [10]. Thus, for purposes of this study, it was necessary to create a working definition for the functional footer based on a reasonable interpretation of the literature. In this study, a functional footer is defined as an expanded footer (more than one or two lines in height) that is separate and distinct from the body of a Web page that provides additional content such as navigation links to other portions of the company website, signup or contact forms, RSS feed links, and/or social media links or icons.

\section{RESEARCH METHODOLOGY}

The underlying research question to this study is: to what extent do companies present footers of different types at their websites? Investigation of this issue provides insight into the degree to which companies have embraced the more recent notion of using a functional footers compared to a traditional footer. The results of a pre-test of websites revealed that websites presented four possible combinations of footers: a traditional footer only, a functional footer only, a functional and traditional footer, or no footers at all. Therefore, for data collection purposes, the functional and traditional footers were treated as independent measures in order to isolate the various combinations of their use.

Three coders conducted a content analysis of INC. 500 company websites in the Spring of 2013. The URLs for the company websites were obtained wherever possible from the INC. 500 list available at this publication's websites. For those organizations that lacked a URL on this list, the researchers used the search engine Google to locate the company's website. The footer measures considered in this study were evaluated based on a review of the company's home page. The inter-coder reliability measures between the coders were .968 for the functional footer and .941 for the traditional footer. These values are consistent with the content analysis guidelines put forth by Neuendorf [12] that inter-coder reliability coefficients of .90 or greater are highly acceptable. In those instances where the coders initially differed, they reexamined the site to reach a consensus on a final decision.

The results of this study are based on 495 websites on the INC. 500 list. Five websites could not be included in this analysis because: (1) their websites were under construction or maintenance; (2) their website could not be opened or was infected with a virus; or (3) the company apparently did not have a website based on no URL entry in the INC. 500 list and no site being found as a result of the Google search.

\section{RESULTS}

As shown in Figure 1, almost two-thirds of the websites in this study (65\%) presented a traditional footer only, compared to about $13 \%$ that included both types of footers and $12 \%$ that displayed only a functional footer. The remaining websites (about 10\%) did not include a footer of any kind. Thus, about one-fourth of companies (25\%) presented a functional footer at their websites. The predominant practice among companies in this study was to present a traditional footer alone. 


\section{Issues in Information Systems \\ Volume 14, Issue 2, pp.182-185, 2013}

\section{Figure 1. Company Website Practices}

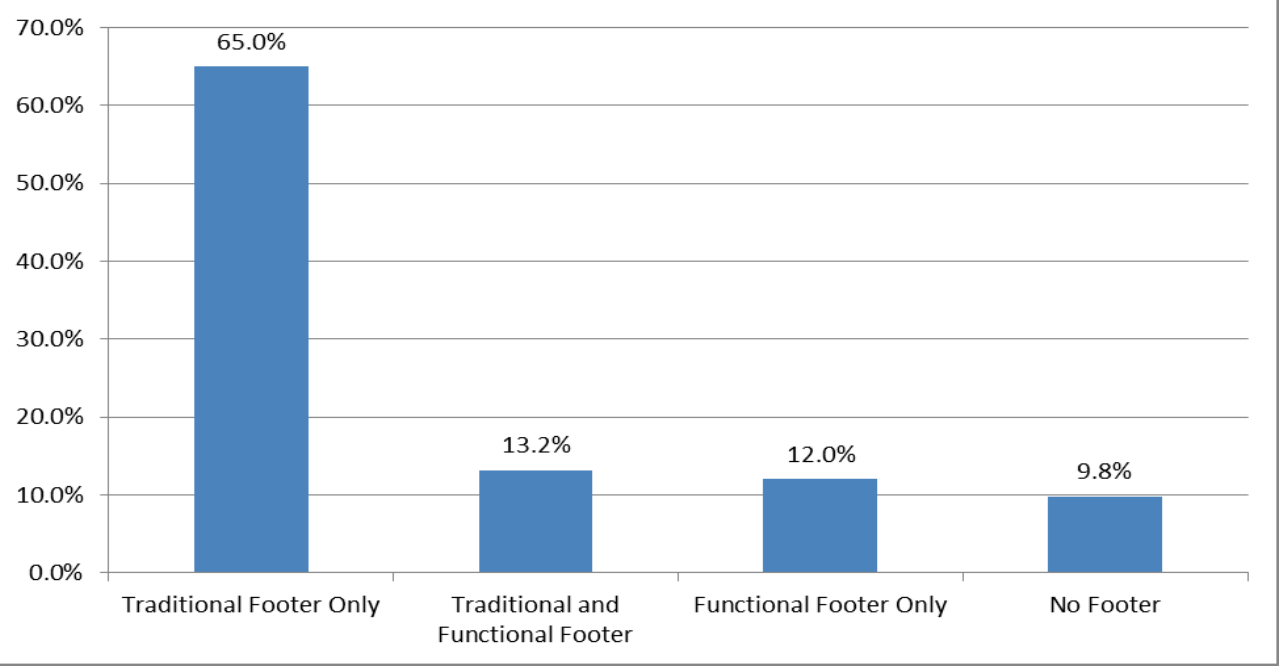

\section{CONCLUSIONS}

Based on this exploratory study, it is clear that company website design practices with respect to the footer show significant variation. While about two-thirds of company sites follow the traditional practice of only displaying an ordinary "one line" footer that contains administrative and/or legal links, about one-fourth of the websites are undertaking a more imaginative approach of using a functional footer of some kind. Unfortunately, since this is a cross-sectional study that collected data at "one point in time", i.e., within a few weeks, no conclusions can be drawn about whether the inclusion of the functional footer at company websites represents a growing trend. That issue would need to be examined in a follow-up, longitudinal study. It should also be noted that the sample used in this study, the websites of INC. 500 companies, which are small to medium sized, high growth businesses, may not be representative of organizations' websites in general. Thus, follow-up studies using other samples such as Fortune 500 company websites are encouraged. Finally, future research could consider whether certain variables such as company size, site type or industry type have any association with the type of footer used at company websites.

Nevertheless, the results suggest that about one-fourth of companies in the sample see value in employing a functional footer in their website design. This raises the possibility that the design of other websites may also be enhanced with the addition of this design feature. A fat footer provides greater convenience and efficiency to website users by making links to the most important or commonly used portions of a website directly available at every page, rather than requiring users who are at the bottom of a page to navigate back to the top to find these links through the navigation menus. An expanded footer also encourages users to stay on a website longer or to initiate contact with the company and it reminds users that the company has a presence at various social media sites.

In short, a functional footer may be used to promote website usability. For this reason, more organizations are encouraged to consider raising the status of their website footer from being "invisible" to giving it nearly as much prominence as the page heading. Granting the footer an upgrade in status appears consistent with what psychologists call the "primacy" and "recency" effects that hold that individuals tend to be most influenced by what they observe first and last [3]. Presenting a more robust footer sends a positive message to users that the site's designers are trying to "take care of users" by delivering value from the top to the bottom of the screen.

As noted earlier, there are many different possibilities as to what content a company can choose to deliver in a functional footer. Which elements to include depend upon the purpose of the site and what users expect. For example, an e-commerce site might include links in the functional footer to the products users purchase most often online. Whatever content is included in the functional footer, like other elements of website design, should be rooted in user testing. By studying a representative sample of users, asking them to perform representative tasks, and 


\section{Issues in Information Systems}

Volume 14, Issue 2, pp.182-185, 2013

observing their behaviors and success rates [11], designers can identify which elements to include in a functional footer that will best promote usability through improved efficiency, effectiveness and user satisfaction.

\section{REFERENCES}

1. Cappel, J. \& Huang, Z. (2007). "A Usability Analysis of Company Websites.” Journal of Computer Information Systems, 48.1, 117-123.

2. Cronin, M. (2009). "Informative and Usable Footers in Web Design." Smashing Magazine, June 17. Available at: http://www.smashingmagazine.com/2009/06/17/informative-and-usable-footers-in-web-design/.

3. Encylopedia.com. "Recency effect." Available at: http://www.encyclopedia.com/doc/1088-recencyeffect.html.

4. Flanders, V. Web Pages That Suck Website. Available at: http://www.webpagesthatsuck.com/.

5. Huang, Z. \& Cappel, J. (2012). "A Comparative Study of Website Usability Practices of Fortune 500 Versus INC. 500 Companies." Information Systems Management, 29.2, 112-122.

6. Johnson, J. (2010). Designing with the Mind in Mind. Burlington, MA: Morgan Kaufman Publishers.

7. Krug, S. Advanced Common Sense website. Available at: www.sensible.com.

8. "Navigation." The Motive Design Glossary. Available at: www.motive.co.nz/glossary/navigation.php.

9. Nielsen Norman Group website. (2010). Available at: www.nngroup.com.

10. Nielsen Norman Group. (2012). "Web Page Design: The Anatomy of High-Performing Web Pages." Usability Week 2012, Toronto, Canada, July 23-27, 2012.

11. Nielsen Norman Group. (2012). "Usability 101: Introduction to Usability." Available at: www.nngroup.com/articles/usability-101-introduction-to-usability/.

12. Neuendorf, K. (2002). The Content Analysis Guidebook. Thousand Oaks, CA: Sage Publications.

13. UI-Patterns.com. "Fat Footer." Available at: www.ui-patterns.com/patterns/FatFooter.

14. Usability.gov. "Your Guide to Developing Usable \& Useful Websites." Available at: www.usability.gov.

15. "Resources: About Usability." User Experience Professionals Association website. Available at: www.upassoc.org/usability_resources/about_usability/defitions_of_usability.html. 